\title{
Split Edge Domination in Boolean Function Graph B(G, L(G), NINC) of a Graph
}

\author{
${ }^{*}$ S. Muthammai ${ }^{1}$ and S. Dhanalakshmi ${ }^{2}$ \\ ${ }^{1}$ Government Arts and Science college, Kadaladi, Tamil Nadu, India. \\ ${ }^{2}$ Government Arts College for Women (Autonomous), Pudukkottai, Tamil Nadu, India. \\ Email:_"muthammai.sivakami@gmail.com, dhanalakshmi8108@gmail.com
}

\begin{abstract}
For any graph $G$, let $V(G)$ and $E(G)$ denote the vertex set and edge set of $G$ respectively. The Boolean function graph $B(G, L(G), N I N C)$ of $G$ is a graph with vertex set $V(G) \cup E(G)$ and two vertices in $B(G, L(G), N I N C)$ are adjacent if and only if they correspond to two adjacent vertices of $G$, two adjacent edges of $G$ or to a vertex and an edge not incident to it in $G$. For brevity, this graph is denoted by $B_{I}(G)$. In this paper, Split edge domination numbers of Boolean Function Graphs of some standard graphs are obtained.
\end{abstract}

Keywords: Boolean Function graph, Edge Domination Number.

\section{Introduction}

Graphs discussed in this paper are undirected and simple graphs. For a graph G, let $\mathrm{V}(\mathrm{G})$ and $\mathrm{E}(\mathrm{G})$ denote its vertex set and edge set respectively. A subset $\mathrm{D}$ of $\mathrm{V}$ is called a dominating set of $G$ if every vertex not in $D$ is adjacent to some vertex in $S$. The domination number $\gamma(\mathrm{G})$ of $\mathrm{G}$ is the minimum cardinality taken over all dominating sets of G. The open neighborhood $\mathrm{N}(\mathrm{v})$ of $\mathrm{v}$ in $\mathrm{V}$ is the set of vertices adjacent to $\mathrm{v}$, and the set $\mathrm{N}[\mathrm{v}]=\mathrm{N}(\mathrm{v}) \cup\{\mathrm{v}\}$ is the closed neighborhood of $\mathrm{v}$. An edge e of a graph is said to be incident with the vertex $\mathrm{v}$ if $\mathrm{v}$ is an end vertex of e. In this case, we also say that $\mathrm{v}$ is incident with e.

A subset $\mathrm{F} \subseteq \mathrm{E}$ is called an edge dominating set of $\mathrm{G}$ if every edge not in $\mathrm{F}$ is adjacent to some edge in $F$. The edge domination number $\gamma^{\prime}(G)$ of $G$ is the minimum cardinality taken over all edge dominating sets of $\mathrm{G}$. An edge dominating set $\mathrm{F} \subseteq \mathrm{E}$ of a connected graph $G$ is a split edge dominating set, if the induced subgraph $<E(G)-F>$ is disconnected. The split edge domination number $\gamma_{s^{\prime}}(\mathrm{G})$ of $\mathrm{G}$ is the minimum cardinality of a split edge dominating set. The maximum order of a partition of $\mathrm{E}$ into edge dominating sets of $G$ is called the edge domatic number of $G$ and is denoted by $\mathrm{d}^{\prime}(\mathrm{G})$. The concept of edge domination was introduced by Mitchell and Hedetniemi [8]. Jayaram [6] studied line (edge) dominating sets and obtained bounds for the line (edge) domination number and obtained Nordhaus-Gaddum results for the line domination number. Arumugam and Velammal [1] have discussed edge domination number and edge domatic number. The complementary edge domination in graphs is studied by Kulli and Soner [7]. 
For graph theoretic notations and terminology, we follow Harary [2]. Janakiraman et al., introduced the concept of Boolean function graphs [3 - 5]. For a real $x,\left\lfloor_{x}\right\rfloor$ denotes the greatest integer less than or equal to $\mathrm{x}$.

Theorem 1.1: [6]. For any (p, q) graph G, $\gamma^{\prime} \leq\lfloor p / 2\rfloor$

Theorem 1.2: [6]. For any (p, q) graph $\mathrm{G}, \gamma^{\prime} \leq \mathrm{q}-\beta_{1}+\mathrm{q}_{0}$, where $\beta_{1}$ is the edge independence number and $\mathrm{q}_{0}$ is the number of isolated edges in $\mathrm{G}$.

Theorem 1.3: [6].For any (p, q) graph G, $\gamma^{\prime} \leq \mathrm{q}-\Delta^{\prime}$, where $\Delta^{\prime}$ denotes the maximum degree of an edge in $\mathrm{G}$.

Observation. [3].

1.4. $G$ and $L(G)$ are induced subgraphs of $B_{1}(G)$.

1.5. Number of vertices in $B_{1}(G)$ is $p+q$ and if $d_{i}=\operatorname{deg}_{G}\left(v_{i}\right), v_{i} \in V(G)$, then the number of edges in $B_{1}(G)$ is $q(p-2)+1 / 2 \sum_{1} \leq_{i} \leq_{p} d_{i}{ }^{2}$.

1.6. The degree of a vertex of $G$ in $B_{1}(G)$ is $q$ and the degree of a vertex of $L(G) e^{\prime}$ in $B_{1}(G)$ is $\operatorname{deg}_{L(G)}\left(e^{\prime}\right)+p-2$. Also if $d^{*}\left(e^{\prime}\right)$ is the degree of a vertex $e^{\prime}$ of $L(G)$ in $B_{1}(G)$, then $0 \leq \mathrm{d}^{\star}\left(\mathrm{e}^{\prime}\right) \leq \mathrm{p}+\mathrm{q}-3$. The lower bound is attained, if $\mathrm{G} \cong \mathrm{K}_{2}$ and the upper bound is attained, if $\mathrm{G} \cong \mathrm{K}_{1, \mathrm{n}}$, for $\mathrm{n} \geq 2$.

Theorem 1.7: [3] $B_{1}(G)$ is disconnected if and only if $G$ is one of the following graphs: $\mathrm{nK}_{1}, \mathrm{~K}_{2}, 2 \mathrm{~K}_{2}$ and $\mathrm{K}_{2} \cup_{\mathrm{nK}}$, for $\mathrm{n} \geq 1$.

In this paper, Split edge domination number of Boolean Function Graph $B(G, L(G)$, NINC) of some standard graphs and its bounds are obtained.

\section{Main Results}

In the following edge domination number of $B_{1}\left(P_{n}\right), B_{1}\left(C_{n}\right), B_{1}\left(K_{1, n}\right)$ are found.

Theorem 2.1:

For the path $P_{n}$ on $n(n \geq 6)$ vertices, $\gamma_{s}^{\prime}\left(B_{1}\left(P_{n}\right)\right) \leq 2(2 n-7)$

Proof: Let $v_{1}, v_{2}, \ldots, v_{n}$ be the vertices and $e_{12}, e_{23}, \ldots, e_{n-1}$, be the edges of $P_{n}$, where $e_{i} i_{i+1}=\left(v_{i}, v_{i+1}\right) i=1,2, \ldots, n-1$. Then $v_{1}, v_{2}, \ldots, v_{n} e_{12}, e_{23}, \ldots, e_{n-1} n_{n} \in V\left(B_{1}\left(P_{n}\right)\right)$.

$B_{1}\left(P_{n}\right)$ has $2 n-1$ vertices and $n^{2}-n-1$ edges.

Let $F_{1}=\left\{\left(v_{1}, e_{n-1, n}\right),\left(v_{1}, e_{23}\right),\left(v_{3}, e_{12}\right),\left(v_{n-2}, v_{n-1}\right),\left(e_{23}, e_{34}\right)\right\}$

$\mathrm{F}_{2}=\mathrm{U}_{\mathrm{i}=4}^{\mathrm{n}-2}\left\{\left(\mathrm{v}_{\mathrm{i}}, \mathrm{e}_{12}\right)\left(\mathrm{v}_{\mathrm{i}}, \mathrm{e}_{23}\right)\right\}$,

$\mathrm{F}_{3}=\mathrm{U}_{\mathrm{i}=3}^{\mathrm{n}-3}\left\{\left(\mathrm{v}_{\mathrm{n}-1}, \mathrm{e}_{\mathrm{i}, \mathrm{i}+1}\right)\right\}$ and $\mathrm{F}_{4}=\mathrm{U}_{\mathrm{i}=3}^{\mathrm{n}-2}\left\{\left(\mathrm{v}_{\mathrm{n}}, \mathrm{e}_{\mathrm{i}, \mathrm{i}+1}\right)\right\}$ 
and let $\mathrm{D}=\mathrm{F}_{1} \cup \mathrm{F}_{2} \cup \mathrm{F}_{3} \cup \mathrm{F}_{4} \subseteq \mathrm{E}\left(\mathrm{B}_{1}\left(\mathrm{P}_{\mathrm{n}}\right)\right) .|\mathrm{D}|=5+2(\mathrm{n}-5)+\mathrm{n}-5+\mathrm{n}-4=$ $2(2 n-7) . D$ is an edge dominating set of $B_{1}(G)$ and $\left\langle V\left(\left(B_{1}\left(P_{n}\right)\right)-D\right\rangle\right.$ is disconnected with two components, one of the components being $K_{4}$ induced by the edges $\left(v_{n-1}, e_{12}\right),\left(v_{n}\right.$, $\left.\mathrm{e}_{12}\right), \quad\left(\mathrm{v}_{\mathrm{n}-1}, \mathrm{e}_{23}\right),\left(\mathrm{v}_{\mathrm{n}}, \mathrm{e}_{23}\right)$. Therefore $\mathrm{D}$ is a split edge dominating set of $\mathrm{B}_{1}\left(\mathrm{P}_{\mathrm{n}}\right)$ and hence $\gamma_{s}^{\prime}\left(B_{1}\left(P_{n}\right)\right) \leq|D|=2(2 n-7)$.

Remark 2.1: $\gamma_{s}^{\prime}\left(B_{1}\left(P_{3}\right)\right)=2$

Let $v_{1}, v_{2}, v_{3}$, be the vertices and $e_{12}, e_{23}$, be the edges of $P_{3}$. Then $v_{1}, v_{2}, v_{3}, e_{12}, e_{23} \in$ $\mathrm{V}\left(\mathrm{B}_{1}\left(\mathrm{P}_{3}\right)\right) . \mathrm{D}=\left\{\left(\mathrm{v}_{1}, \mathrm{e}_{23}\right),\left(\mathrm{v}_{3}, \mathrm{e}_{12}\right)\right\}$ is a minimum split edge dominating set of $\mathrm{B}_{1}\left(\mathrm{P}_{3}\right)$. Therefore, $\gamma_{s}^{\prime}\left(\mathrm{B}_{1}\left(\mathrm{P}_{3}\right)\right)=4$.

Remark 2.2: $\gamma_{s}^{\prime}\left(B_{1}\left(P_{4}\right)\right)=4$

Let $\mathrm{v}_{1}, \mathrm{v}_{2}, \mathrm{v}_{3}, \mathrm{v}_{4}$ be the vertices and $\mathrm{e}_{12}, \mathrm{e}_{23}, \mathrm{e}_{34}$ be the edges of $\mathrm{P}_{4}$. Then $\mathrm{v}_{1}, \mathrm{v}_{2}, \mathrm{v}_{3}, \mathrm{v}_{4}$, $\mathrm{e}_{12}, \mathrm{e}_{23}, \mathrm{e}_{34} \in \mathrm{V}\left(\mathrm{B}_{1}\left(\mathrm{P}_{4}\right)\right) . \quad \mathrm{D}=\left\{\left(\mathrm{v}_{2}, \mathrm{v}_{3}\right),\left(\mathrm{v}_{4}, \mathrm{e}_{23}\right),\left(\mathrm{v}_{1}, \mathrm{e}_{34}\right),\left(\mathrm{e}_{12}, \mathrm{e}_{23}\right)\right\}$ is a minimum split edge dominating set of $\mathrm{B}_{1}\left(\mathrm{P}_{4}\right)$. Therefore, $\gamma_{\mathrm{s}}^{\prime}\left(\mathrm{B}_{1}\left(\mathrm{P}_{4}\right)\right)=4$.

Remark 2.3: $\gamma_{s}^{\prime}\left(B_{1}\left(P_{5}\right)\right)=6$

Let $\mathrm{v}_{1}, \mathrm{v}_{2}, \mathrm{v}_{3}, \mathrm{v}_{4}, \mathrm{v}_{5}$ be the vertices and where $\mathrm{e}_{\mathrm{i}},_{\mathrm{i}+1}=\left(\mathrm{v}_{\mathrm{i}}, \mathrm{v}_{\mathrm{i}+1}\right) \mathrm{i}=1,2,3,4,5$ be the edges of $P_{5}$. Then $v_{1}, v_{2}, v_{3}, v_{4}, v_{5}, e_{12}, e_{23}, e_{34}, e_{45} \in V\left(B_{1}\left(P_{5}\right)\right)$. The set $D=\left\{\left(v_{3}, v_{4}\right),\left(v_{1}, e_{23}\right)\right.$, $\left.\left(\mathrm{v}_{1}, \mathrm{e}_{45}\right),\left(\mathrm{v}_{3}, \mathrm{e}_{12}\right),\left(\mathrm{v}_{5}, \mathrm{e}_{34}\right),\left(\mathrm{e}_{23}, \mathrm{e}_{34}\right)\right\}$ is a minimum split edge dominating set of $\mathrm{B}_{1}\left(\mathrm{P}_{5}\right)$. Therefore, $\gamma_{s}^{\prime}\left(B_{1}\left(P_{5}\right)\right)=6$.

\section{Theorem 2.2:}

For the cycle $C_{n}(n \geq 6)$ on $n$ vertices, $\gamma_{s}^{\prime}\left(B_{1}\left(C_{n}\right)\right) \leq 2(2 n-6)=4(n-3)$.

Proof: Let $v_{1}, v_{2}, \ldots, v_{n}$ be the vertices and $e_{12}, e_{23}, \ldots, e_{n-1},_{n}$ be the edges of $C_{n}$, where $e_{i},_{i+1}=$ $\left(v_{i}, v_{i+1}\right) i=1,2, \ldots, n-1$ and $e_{n 1}=\left(v_{n}, v_{1}\right)$. Then $v_{1}, v_{2}, \ldots, v_{n} e_{12}, e_{23}, \ldots, e_{n-1}, e_{n 1} \in$ $\mathrm{V}\left(\mathrm{B}_{1}(\mathrm{Cn})\right) \cdot \mathrm{B}_{1}\left(\mathrm{C}_{\mathrm{n}}\right)$ has $2 \mathrm{n}$ vertices and $\mathrm{n}^{2}$ edges.

Let $F_{1}=\left\{\left(v_{1}, e_{n-1, n}\right),\left(v_{1}, e_{23}\right),\left(v_{3}, e_{12}\right),\left(v_{n-2}, v_{n-1}\right),\left(e_{23}, e_{34}\right),\left(v_{n-1}, e_{n 1}\right),\left(e_{12}, e_{n 1}\right)\right\}$

$\mathrm{F}_{2}=\mathrm{U}_{\mathrm{i}=4}^{\mathrm{n}-2}\left\{\left(\mathrm{v}_{\mathrm{i}}, \mathrm{e}_{12}\right)\left(\mathrm{v}_{\mathrm{i}}, \mathrm{e}_{23}\right)\right\}$,

$\mathrm{F}_{3}=\mathrm{U}_{\mathrm{i}=3}^{\mathrm{n}-3}\left\{\left(\mathrm{v}_{\mathrm{n}-1}, \mathrm{e}_{\mathrm{i}, \mathrm{i}+1}\right)\right\}$ and $\mathrm{F}_{4}=\mathrm{U}_{\mathrm{i}=3}^{\mathrm{n}-2}\left\{\left(\mathrm{v}_{\mathrm{n}}, \mathrm{e}_{\mathrm{i}, \mathrm{i}+1}\right)\right\}$

and let $\mathrm{D}=\mathrm{F}_{1} \cup \mathrm{F}_{2} \cup \mathrm{F}_{3} \cup \mathrm{F}_{4} \subseteq \mathrm{E}\left(\mathrm{B}_{1}\left(\mathrm{C}_{\mathrm{n}}\right) .|\mathrm{D}|=7+2(\mathrm{n}-5)+\mathrm{n}-5+\mathrm{n}-4=4 \mathrm{n}-\right.$ $12=4(n-3) . \quad D$ is an edge dominating set of $B_{1}\left(C_{n}\right)$ and $\left\langle V\left(B_{1}\left(C_{n}\right)\right)-D\right\rangle$ is disconnected with two components, one of the components being $\mathrm{K}_{4}$. Therefore $\mathrm{D}$ is a split edge dominating set of $B_{1}\left(C_{n}\right)$ and hence $\gamma_{s}^{\prime}\left(B_{1}\left(C_{n}\right)\right) \leq|D|=4(n-3)$. 
Remark 2.4: $\gamma_{s}^{\prime}\left(B_{1}\left(C_{3}\right)\right)=4$

Let $v_{1}, v_{2}, v_{3}$ be the vertices and $e_{12}, e_{13}, e_{23}$ be the edges of $C_{3}$. Then $v_{1}, v_{2}, v_{3}, e_{12}, e_{13}$, $e_{23} \in V\left(B_{1}\left(C_{3}\right)\right) . D=\left\{\left(v_{2}, v_{3}\right),\left(v_{1}, e_{23}\right),\left(v_{2}, e_{13}\right),\left(e_{12}, e_{23}\right)\right\}$ is a minimum split edge dominating set of $B_{1}\left(C_{3}\right)$. Therefore, $\gamma_{s}^{\prime}\left(B_{1}\left(C_{3}\right)=4\right.$.

Remark 2.5: $\gamma_{s}^{\prime}\left(B_{1}\left(C_{4}\right)\right)=6$

Let $v_{1}, v_{2}, v_{3}, v_{4}$ be the vertices and $e_{12}, e_{14}, e_{23}, e_{34}$ be the edges of $C_{4}$. Then $v_{1}, v_{2}, v_{3}$, $\mathrm{v}_{4}, \mathrm{e}_{12}, \mathrm{e}_{14}, \mathrm{e}_{23}, \mathrm{e}_{34} \in \mathrm{V}\left(\mathrm{B}_{1}\left(\mathrm{C}_{4}\right)\right) . \mathrm{D}=\left\{\left(\mathrm{v}_{1}, \mathrm{v}_{4}\right),\left(\mathrm{v}_{2}, \mathrm{v}_{3}\right),\left(\mathrm{v}_{3}, \mathrm{e}_{14}\right),\left(\mathrm{v}_{4}, \mathrm{e}_{23}\right),\left(\mathrm{e}_{12}, \mathrm{e}_{14}\right),\left(\mathrm{e}_{23}, \mathrm{e}_{34}\right)\right\}$ is a minimum split edge dominating set of $B_{1}\left(C_{4}\right)$. Therefore, $\gamma_{s}^{\prime}\left(B_{1}\left(C_{4}\right)\right)=6$.

Remark 2.6: $\gamma_{s}^{\prime}\left(B_{1}\left(C_{5}\right)\right)=8$

Let $\mathrm{v}_{1}, \mathrm{v}_{2}, \mathrm{v}_{3}, \mathrm{v}_{4}, \mathrm{v}_{5}$ be the vertices and $\mathrm{e}_{12}, \mathrm{e}_{23}, \mathrm{e}_{34}, \mathrm{e}_{45}, \mathrm{e}_{15}$ be the edges of $\mathrm{C}_{5}$. Then $\mathrm{v}_{1}, \mathrm{v}_{2}, \mathrm{v}_{3}, \mathrm{v}_{4}, \mathrm{v}_{5}, \mathrm{e}_{12}, \mathrm{e}_{23}, \mathrm{e}_{34}, \mathrm{e}_{45}, \mathrm{e}_{15} \in \mathrm{V}\left(\mathrm{B}_{1}\left(\mathrm{P}_{5}\right)\right)$. The set $\mathrm{D}=\left\{\left(\mathrm{v}_{1}, \mathrm{e}_{23}\right),\left(\mathrm{v}_{2}, \mathrm{v}_{3}\right),\left(\mathrm{v}_{4}, \mathrm{v}_{5}\right),\left(\mathrm{v}_{2}, \mathrm{e}_{34}\right)\right.$, $\left.\left(v_{4}, e_{15}\right),\left(v_{5}, e_{12}\right),\left(e_{12}, e_{23}\right),\left(e_{34}, e_{45}\right)\right\} \quad$ is a minimum split edge dominating set of $B_{1}\left(C_{5}\right)$. Therefore, $\gamma_{s}^{\prime}\left(B_{1}\left(C_{5}\right)\right)=8$.

\section{Theorem 2.3:}

For the star $K_{1, n}$ on $(n+1)$ vertices, $\gamma_{s}^{\prime}\left(B_{1}\left(K_{1, n}\right)\right) \leq n(n-1), \quad n \geq 2$.

Proof: Let $v_{1}, v_{2}, \ldots, v_{n+1}$ be the vertices of $K_{1, n}$ with $v_{1}$ as the central vertex, where $e_{i}=\left(v_{1}, v_{j}\right), \quad i=2,3, \ldots, n+1 . B_{1}\left(K_{1, n}\right)$ has $(2 n+1)$ vertices and $n(3 n-1) / 2$ edges. Then $v_{1}, v_{2}, \ldots, v_{n} e_{1}, e_{2}, \ldots, e_{n} \in V\left(B_{1}\left(K_{1, n}\right)\right)$.

$\mathrm{E}\left(\mathrm{B}_{1}\left(\mathrm{~K}_{\mathrm{l}, \mathrm{n}}\right)=\mathrm{E}\left(\mathrm{K}_{\mathrm{l}, \mathrm{n}}\right) \cup \mathrm{E}\left(\mathrm{K}_{\mathrm{n}}\right) \cup\left\{\left(\mathrm{v}_{\mathrm{i}}, \mathrm{e}_{\mathrm{j}}\right) / 1 \leq \mathrm{I} \leq \mathrm{n}, 1 \leq \mathrm{j} \leq \mathrm{n}, \mathrm{i} \neq \mathrm{j}\right\}\right.$.

Let $\mathrm{D}=\left\{\left(\mathrm{v}_{\mathrm{i}}, \mathrm{e}_{\mathrm{j}}\right) / 1 \leq_{\mathrm{i}} \leq \mathrm{n}, 1 \leq \mathrm{j} \leq \mathrm{n}, \mathrm{i} \neq \mathrm{j}\right\}$ and $|\mathrm{D}|=\mathrm{n}(\mathrm{n}-1)$. Then $\mathrm{D}$ is an edge dominating set of $\mathrm{B}_{1}\left(\mathrm{~K}_{1, \mathrm{n}}\right) \cdot \mathrm{V}\left(\mathrm{B}_{1}\left(\mathrm{~K}_{1, \mathrm{n}}\right)\right)-\mathrm{D}$ is disconnected with the components $\mathrm{K}_{1, \mathrm{n}}$ and $K_{n}$. Therefore, $D$ is a split edge dominating set of $B_{1}\left(K_{1, n}\right)$. Hence, $\gamma_{s}^{\prime}\left(B_{1}\left(K_{1, n}\right)\right) \leq|D|=$ $\mathrm{n}(\mathrm{n}-1)$

\section{Theorem 2.4:}

For any connected graph $G, \gamma_{s}^{\prime}\left(B_{1}(G)\right) \leq(p+q)-\left(\beta_{1}(G)+\beta_{1}^{\prime}(G)+1\right)$, where $\beta_{1}(G)$ and $\beta_{1}^{\prime}(G)$ is the independence numbers of $G$ and $L(G)$ respectively.

Proof: Let $\mathrm{D}^{\prime}$ and $\mathrm{D}^{\prime \prime}$ be edge independent sets of $\mathrm{G}$ and $\mathrm{L}(\mathrm{G})$ respectively, such that $\left|D^{\prime}\right|=\beta_{1}(G)$ and $\left|D^{\prime \prime}\right|=\beta_{1}^{\prime}(G)$. Let $e=(u, v) \in D^{\prime}$ and let $w \in V(G)$ be adjacent to v. Then $(w, e) \in E\left(B_{1}(G)\right)$. Let $D^{\prime \prime \prime}=\{(w, e)\}$ and $D=\left(B_{1}(G)\right)-\left(D^{\prime} \cup D^{\prime \prime} \cup D^{\prime \prime \prime}\right)$. Then $\mathrm{D}$ is an edge dominating set of $\mathrm{B}_{1}(\mathrm{G})$ and $\langle\mathrm{D}\rangle$ is disconnected, one of the 
components being $K_{2}$. Therefore, D is a split edge dominating set of $B_{1}(G)$ and hence $\gamma_{s}^{\prime}\left(B_{1}(G)\right) \leq|D|=(p+q)-\left(\beta_{1}(G)+\beta_{1}^{\prime}(G)+1\right)$.

Equality holds $G \cong P_{3} . \beta_{1}\left(P_{3}\right)=1, \beta_{1}^{\prime}\left(P_{3}\right)=1$ implies that $\gamma_{s}^{\prime}\left(B_{1}\left(P_{3}\right)\right)=(p+q)-3=3+2-3=2$.

\section{Theorem 2.5:}

For any connected graph $\mathrm{G}, \quad \gamma_{s}^{\prime}\left(\mathrm{B}_{1}(\mathrm{G})\right) \leq \mathrm{q}$.

Proof: Let $v_{1}, v_{2}, \ldots, v_{p}$ be the vertices of $G$ and let $e_{i} \in E(G)$ be not incident with $v_{i}, i=1$, $2, \ldots, p$. Let $D=\left\{\left(v_{i}, e_{i}\right), i=1,2, \ldots p\right\}$. Then $D^{\prime}=V\left(B_{1}(G)\right)-D$ is an edge dominating set of $B_{1}(G)$ and $<D^{\prime}>\cong \mathrm{pK}_{2}$. Therefore, $D^{\prime}$ is a split edge dominating set of $B_{1}(G)$ and $\gamma_{s}^{\prime}\left(B_{1}(G)\right) \leq\left|D^{\prime}\right|=p+q-|D|=p+q-p=q$.

Equality holds if $\mathrm{G} \cong \mathrm{K}_{1,2}, \mathrm{P}_{4}$.

\section{Theorem 2.6:}

Let $G$ be a connected (p, q) graph. Then $\gamma_{s}^{\prime}\left(B_{1}(G)\right) \leq 2(q-\delta(G)-1)+p$

Proof: Let e $\in \mathrm{V}(\mathrm{L}(\mathrm{G}))$ be a vertex of maximum degree in $\mathrm{L}(\mathrm{G})$. Then e $\in \mathrm{E}(\mathrm{G})$.

Let $\mathrm{e}=(\mathrm{u}, \mathrm{v}) \in \mathrm{E}(\mathrm{G})$ and let $\operatorname{deg}_{\mathrm{G}}(\mathrm{u})=\mathrm{m}$ and $\operatorname{deg}_{\mathrm{G}}(\mathrm{v})=\mathrm{n}$. Then $\operatorname{deg}_{\mathrm{L}(\mathrm{G})} \mathrm{e}=\mathrm{m}+\mathrm{n}-2$. Let $\mathrm{D}^{\prime}$ and $\mathrm{D}^{\prime \prime}$ be the sets of edges not incident with $\mathrm{u}$ and $\mathrm{v}$ respectively. Then $\left|\mathrm{D}^{\prime}\right|=$ $\mathrm{q}-\mathrm{m}$ and $\left|\mathrm{D}^{\prime \prime}\right|=\mathrm{q}-\mathrm{n}$. Let $\mathrm{D}^{\prime \prime \prime}$ be the set of edges of G adjacent to e. Therefore $\left|D^{\prime \prime \prime}\right|=\operatorname{deg}_{\mathrm{L}(\mathrm{G})}$. Let $S$ be the set of vertices in $\mathrm{G}$ adjacent to none of $\mathrm{u}$ and $\mathrm{v}$.

Let $S^{\prime}=\{(w, e) / w \in S\} .\left|S^{\prime}\right|=p-\left(\operatorname{deg}_{G} u+\operatorname{deg}_{G} v\right) \leq p-2 \delta(G)$. If $D=D^{\prime} \cup D^{\prime \prime} \cup$ $\mathrm{D}^{\prime \prime \prime} \cup \mathrm{S}^{\prime}$, then $\mathrm{D} \subseteq \mathrm{E}\left(\mathrm{B}_{1}(\mathrm{G})\right)$ is an edge dominating set of $\mathrm{B}_{1}(\mathrm{G})$ and $\mathrm{e}$ is an isolated edge in $<\mathrm{V}\left(\mathrm{B}_{1}(\mathrm{G})\right)-\mathrm{D}>$ and hence $\mathrm{D}$ is a split edge dominating set of $\mathrm{B}_{1}(\mathrm{G})$ and

$$
\begin{aligned}
\gamma_{\mathrm{s}}^{\prime}\left(\mathrm{B}_{1}(\mathrm{G})\right) \leq|\mathrm{D}| & \leq \mathrm{q}-\mathrm{m}+\mathrm{q}-\mathrm{n}+\operatorname{deg}_{\mathrm{L}(\mathrm{G})} \mathrm{e}+\mathrm{p}-2 \delta(\mathrm{G}) \\
& =2 \mathrm{q}-\left(\operatorname{deg}_{\mathrm{L}(\mathrm{G})} \mathrm{e}+2\right)+\operatorname{deg}_{\mathrm{L}(\mathrm{G})} \mathrm{e}+\mathrm{p}-2 \delta(\mathrm{G})=2 \mathrm{q}+\mathrm{p}-2 \delta(\mathrm{G})-2 .
\end{aligned}
$$

Equality holds if $\mathrm{G} \cong \mathrm{C}_{\mathrm{n}}$.

\section{Conclusion}

In this paper, split edge domination numbers of Boolean Function Graph $B(G, L(G)$, NINC ) of path, cycle, stars and bounds are obtained. 


\section{References:}

[1] S. Arumugam and S.Velammal, Edge domination in graphs, Tairwanese Journal of Mathematics, Vol. 2, pp.173-179, 1998.

[2] Harary F, Graph Theory, Addison, - Wesley Reading Mass., 1969.

[3] T. N. Janakiraman, S. Muthammai, M. Bhanumathi, Domination Numbers on the Boolean Function Graph of a Graph, Mathematica Bohemica, 130(2005), No.2, 135-151.

[4] T. N. Janakiraman, S. Muthammai, M. Bhanumathi, Domination Numbers on the Complement of the Boolean Function Graph of a Graph, Mathematica Bohemica, 130(2005), No.3, pp. 247-263.

[5] T. N. Janakiraman, S. Muthammai, M. Bhanumathi, On the Boolean Function Graph of a Graph and on its Complement, Mathematica Bohemica, 130(2005), No.2, pp. 113-134.

[6] R. Jayaram, Line domination in graphs, Graphs and Combinatorics, Vol.3, No.4, pp.357-363, 1987.

[7] R.Kulli and N.D.Soner, Complementary edge domination in graphs, Indian Journal of Pure and Applied Mathematics, Vol.28, No.7, pp. 917-920, 1997.

[8] S.Mitchell and S.T.Hedetniemi, Edge domination in trees, Congressus Numerantium, Vol. 19, pp. 489-509, 1977.

\section{Authors' Profile:}

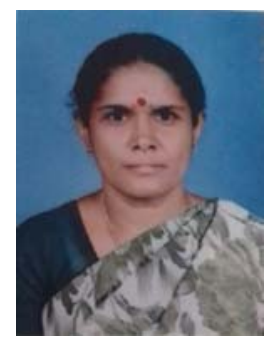

Dr. S. Muthammai received the M.Sc and M.Phil degree in Mathematics from Madurai Kamaraj University, Madurai in 1982 and 1983 respectively and the Ph.D. degree in Mathematics from Bharathidasan University, Tiruchirappalli in 2006 under the guidance of Dr.T.N.Janakiraman, Department of Mathematics, National Institute of Technology, Tiruchirappalli. From $16^{\text {th }}$ September 1985 to $12^{\text {th }}$ October 2016, she has been with the Government Arts College for women(Autonomous), Pudukkottai, Tamilnadu, India and she is currently Principal(Retd), Alagappa Arts College, Karaikudi, Tamilnadu. Her main area research is Domination in Graph Theory.

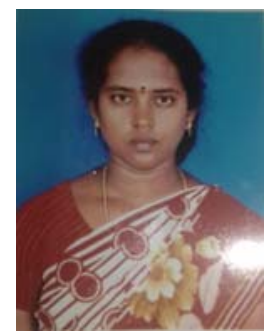

S. Dhanalakshmi was born in Pudukkottai, Tamilnadu, India in 1981. She received the B.Sc degree in Mathematics from the Bharathidasan University, Tiruchirappalli, in 2001, M.Sc degree in Mathematics from the Bharathidasan University, Tiruchirappalli, in 2003, M.Phil degree in Mathematics from the Bharathidasan University, Tiruchirappalli, in 2006 and B.Ed degree in Mathematics from the Tamilnadu University, in 2009. She has 9 years teaching experience in our college. She is pursuing research in the Department of Mathematics at Government Arts College for Women (A), Pudukkottai, Tamilnadu, India. Her main area research is Domination in Graph Theory. 